Check for updates

Cite this: RSC Adv., 2019, 9, 24267

\title{
Structural analysis and antioxidant activity of an arabinoxylan from Malvastrum coromandelianum $\mathrm{L}$. (Garcke)
}

\begin{abstract}
Shanti Devi, Ajeet K. Lakhera and Vineet Kumar (DD*
Malvastrum coromandelianum L. (Garcke) is extensively used in traditional medicinal systems to treat various ailments. In the present study, an alkali-soluble polysaccharide (MAP) was isolated from the leaves of M. coromandelianum in $1.15 \%(\mathrm{w} / \mathrm{w})$ yield. MAP was composed of L-rhamnose, L-arabinose, Dxylose, D-glucose and D-galactose in a 1.00:6.04:19.88:1.07:3.03 molar ratio along with Dglucuronic acid (1.95). Methylation/linkage analysis revealed a backbone of $\rightarrow 4)$ - $\beta$-D-Xylp( $\rightarrow$ (30.09 mol\%) with a side chain of $\rightarrow 3)-\alpha-L-A r a f(1 \rightarrow(15.21 \mathrm{~mol} \%)$ residues. The structure of MAP was elucidated by a combination of degradative and derivatization techniques, including hydrolysis, alditol acetate derivatization, methylation, GC-MS, partial hydrolysis, ESI-MS and NMR (1D, 2D) spectral analysis. Based on correlation analysis, MAP was found to be an arabinoxylan comprising a backbone of $\rightarrow 4)$ - $\beta$ D-linked Xylp $(1 \rightarrow$ with branching at O-2 by a $\rightarrow 3)-\alpha-L-A r a f(1 \rightarrow$ and $\rightarrow 3)-\beta-D-X y l p(1 \rightarrow$ chain. MAP also exhibited ferric ion reducing activity, with a reducing power of $0.914 \pm 0.01\left(R^{2}=0.972\right)$ at $1 \mathrm{mg} \mathrm{mL}^{-1}$ concentration, which showed dose-dependent behavior. MAP can be utilized as a potential antioxidant.
\end{abstract}

Received 4th March 2019 Accepted 8th July 2019

DOI: 10.1039/c9ra01629e

rsc.li/rsc-advances
ROS production. Lycium barbarum polysaccharides enhance the activities of superoxide dismutase (SOD) and glutathione peroxidase (GSH-Px) in chickens. ${ }^{11}$ Ganoderma lucidum polysaccharides exhibit in vitro antioxidant activities. ${ }^{\mathbf{1 2}}$ A polysaccharide from Cordyceps sinensis slows ROS generation by inhibiting PDGF-BB-induced inflammation. ${ }^{13}$ An extracellular polysaccharide from Morchella can significantly improve the activity of enzymes, viz., GSH-Px and SOD in the blood, spleen, heart, liver, and kidneys of mice and decrease the malondialdehyde content in these organs. ${ }^{\mathbf{1 4}}$

Therefore, polysaccharides from plants are a promising source of antioxidants, which can effectively prevent damage due to oxidative stress and hence prevent diseases. In our laboratory, the polysaccharides from plant species used in traditional medicine are being characterized, and their activity profiles are being studied to provide leads for future drug development based on their structure-activity relationships. ${ }^{15-19}$ In our continuous endeavor towards this goal, it was observed that a polysaccharide from Malvastrum coromandelianum (Garcke) Linn showed significant ferric ion reducing ability using the potassium ferricyanide assay. Interestingly, $M$. coromandelianum is an alien weed species found throughout India; ${ }^{\mathbf{2 0} 21}$ it is known to possess diverse pharmacological and biological activities. The species is reported to have emollient, resolvent, bechic and antidysenteric properties, and it is widely used in traditional systems of medicine as an anti-inflammatory and analgesic agent and also to treat ulcers,$^{22}$ stomachache ${ }^{23}$ jaundice, etc. Its flowers are used to treat cough along with chest and 
lung diseases. ${ }^{24}$ Different parts of the species are employed in diverse herbal formulations to treat gout, ${ }^{25}$ rheumatic arthralgia, ${ }^{26}$ laying hen salpingitis,${ }^{27}$ otitis,${ }^{28}$ and tumors $;^{29}$ it is also used in herbicidal compositions ${ }^{30}$ and medicinal wine. ${ }^{31}$

Pharmacological screening of the aqueous extract exhibited significant antidiabetic and antihyperlipidemic activities. ${ }^{32,33}$ The extract also inhibited inflammation induced by carrageenan and pain due to formalin stimulation. ${ }^{34}$ A crude water extract from the aerial parts exhibited antibacterial activity against methicillin-resistant strains of Staphylococcus aureus. ${ }^{35,36}$ Further, in view of the fact that natural plant polysaccharides are currently gaining significant popularity as potent natural antioxidants, concomitant with the vast pharmacological activity of the species, it was hypothesized that the polysaccharide constituting the major fraction of water extract of $M$. coromandelianum is responsible for its activity. However, to date, there have been no studies regarding the purification, characterization or antioxidant activities of polysaccharides from $M$. coromandelianum.

In the present study, a polysaccharide was isolated from leaves of $M$. coromandelianum using $1 \mathrm{M} \mathrm{NaOH}$ solution, and its ferric reducing power activity was examined using the potassium ferricyanide assay. Interestingly, the polysaccharide showed positive results and was found to significantly reduce ferric ions in a dose-dependent manner. Thus, it was thought to be worthwhile to explore the structure of the alkali soluble polysaccharide (MAP) from the species. The structural characterization was carried out via chemical degradation and derivatisation methods, viz. hydrolysis, alditol acetates, and methylation, concomitant with GC-MS and ESI-MS analysis. The results were further corroborated by $1 \mathrm{D}$ and $2 \mathrm{D}$ NMR spectroscopy $\left({ }^{1} \mathrm{H},{ }^{13} \mathrm{C}\right.$, HSQC and HMBC). Structural analysis of the polysaccharide may lead to enhanced utilization of this species in diverse biological and pharmaceutical applications in addition to other industrial applications based on its structure-activity relationship. The encouraging results of our investigation offer a strong basis for the development of novel polysaccharide-based antioxidants from this species.

\section{Experimental}

\subsection{Materials}

The leaves of $M$. coromandelianum were collected from the Forest Research Institute campus, Dehradun in July 2014. The species was authenticated by Dr H. B. Naithani, Systematic Botanist, Botany Division, and voucher specimen no. 170580 was deposited at the herbarium of Systematic Botany Discipline, Botany Division, Forest Research Institute, Dehradun.

All the chemicals and reagents used were of analytical grade. The standard solutions were freshly prepared before experimentation. Sephadex G-200 was purchased from Pharmacia, Stockholm, Sweden. Dialysis membrane with a molecular weight cutoff (MWCO) of 12 to $14 \mathrm{kDa}$ was procured from Himedia Laboratories Pvt. Ltd., Mumbai, India. UV-vis spectra were recorded on a Thermo Scientific Spectrascan UV 2700 spectrophotometer.

\subsection{Isolation, purification and homogeneity analysis of the polysaccharide}

The leaves of $M$. coromandelianum were washed thoroughly under running water and dried in shade at room temperature. The polysaccharide was extracted by following the method of Kumar and Kumar. ${ }^{16}$ Briefly, air dried leaves $(100 \mathrm{~g})$ were shredded and extracted with distilled water at $30{ }^{\circ} \mathrm{C}$ with continuous stirring for $3 \mathrm{~h}$ (3 times) followed by filtration. The obtained residue was stirred at $80{ }^{\circ} \mathrm{C}$ for $3 \mathrm{~h}$ ( 3 times) to isolate the hot water-soluble polysaccharide. Further, the residue left after hot water extraction was stirred with $1 \mathrm{M} \mathrm{NaOH}$ solution at ambient temperature for $1 \mathrm{~h}$ and filtered. The filtrate was neutralized using $0.5 \mathrm{M} \mathrm{HCl}$ and centrifuged at $2000 \mathrm{rpm}$ for 15 minutes to remove all undissolved impurities. The supernatant was concentrated to a small volume and poured into 3 volumes of ethanol with constant stirring. The polysaccharide precipitated as a fluffy mass and was separated by centrifugation. The precipitates were again dissolved in a minimum quantity of water and re-precipitated with ethanol. This step was repeated two times. The obtained polysaccharide was washed sequentially with diethyl ether, acetone, and ethanol to eliminate impurities. The supernatant was decanted off every time. The precipitates were dried and dissolved in a minimum amount of distilled water $(50 \mathrm{~mL})$ and the undissolved mass was removed by ultracentrifugation at $12000 \mathrm{rpm} .{ }^{37}$ The supernatant was freeze dried to obtain the crude alkali-soluble polysaccharide.

A dilute solution (5 mg $\mathrm{mL}^{-1}$ ) of alkali-soluble polysaccharide was passed through a freshly regenerated cation exchange resin column [Dowex-50 W-X8] followed by an anion exchange resin column [Seralite SRA-400], and the eluents were analyzed by the Molisch carbohydrate test. ${ }^{38}$ The combined eluents were concentrated to a small volume and dialyzed against distilled water using a dialysis membrane (MWCO: 12 to $14 \mathrm{kDa}$ ) for $72 \mathrm{~h}$. The dialyzed solution was concentrated and reprecipitated with four volumes of ethanol. The precipitates were separated, dried, dissolved in distilled water and lyophilized to obtain the crude polysaccharide as an off-white amorphous mass (1.15 g).

\subsection{Gel permeation chromatography of MAP}

The homogeneity analysis of the crude polysaccharide was performed using GPC. A Pharmacia column $(1.6 \times 40 \mathrm{~cm})$ was packed with Sephadex G-200 as a gel permeation medium using double distilled water as the mobile phase, and $200 \mathrm{mg}$ (MAP) polysaccharide was loaded. Fractions of $2.5 \mathrm{~mL}$ each at an elution rate of $0.30 \mathrm{~mL} \min ^{-1}$ were collected using a Gilson fraction collector (Model-202). The absorbance of the fractions was studied using the anthrone-sulphuric acid method ${ }^{39}$ at $620 \mathrm{~nm}$, and a graph was plotted of absorbance $v s$. the fractions collected after elution. The fractions comprising the major peak were pooled, dialyzed and lyophilized to obtain the pure native alkali-soluble polysaccharide, which was designated as MAP. 


\subsection{Complete hydrolysis and paper chromatography}

MAP (5 mg) was completely hydrolyzed by refluxing with $2 \mathrm{~N}$ sulphuric acid $(5 \mathrm{~mL})$ for $25 \mathrm{~h}$ followed by neutralization using barium carbonate slurry; then, it was filtered and concentrated to a syrupy liquid. The resulting liquid was subjected to paper chromatography along with standard monosaccharides using 1 chr and $3 \mathrm{chr}$ Whatman chromatography paper. The papers were run for 45 to $120 \mathrm{~h}$ using the following solvent systems; (a) $n$-butanol : formic acid : water; $12: 1: 7$ (upper layer); (b) $n$ butanol :pyridine :water; $6: 4: 3$; and (c) ethyl acetate : acetic acid : $n$-butanol : water; $4: 3: 2: 2$. The paper chromatograms were dried at room temperature, followed by detection of the monosaccharides (neutral and acidic) using aniline phthalate spray and ammoniacal silver nitrate complex independently by employing standard protocols. ${ }^{40}$

\subsection{Carboxyl reduction of polysaccharide}

MAP was reduced using the method by Taylor, Shively and Conard. ${ }^{41}$ The polysaccharide $(50 \mathrm{mg})$ solution in distilled water $(100 \mathrm{~mL})$ was adjusted to $\mathrm{pH} 4.75$ using $1 \mathrm{M} \mathrm{HCl}$. To the resulting solution, solid 1-ethyl-3-(3-dimethylaminopropyl) carbodimide hydrochloride $(167 \mathrm{mg}, \mathrm{EDC} \cdot \mathrm{HCl})$ was added.

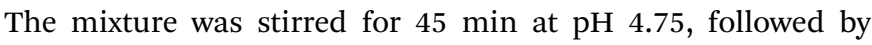
dropwise addition of $3 \mathrm{M} \mathrm{NaBH}_{4}$ solution at $25{ }^{\circ} \mathrm{C}$ during a one hour period. During the addition of sodium borohydride, the $\mathrm{pH}$ was maintained at $7.0 \mathrm{using} 4 \mathrm{M} \mathrm{HCl}$ solution. At this stage, the reaction mixture was further stirred for $1 \mathrm{~h}$, and the $\mathrm{pH}$ of the solution was decreased to 4 by addition of dil. $\mathrm{HCl}(1 \mathrm{M})$ to destroy excess sodium borohydride. The resulting solution was dialyzed (12 to $14 \mathrm{kDa}$ ) exhaustively against distilled water for $72 \mathrm{~h}$, concentrated to a small volume and precipitated by addition of ethanol. The precipitates were filtered, dissolved in a minimum quantity of water and lyophilized to obtain the reduced polysaccharide (MAP-R; $31 \mathrm{mg}$ ). The complete reduction of the polysaccharide was analyzed and confirmed by the negative carbazole-sulphuric acid color test for uronic acid.

\subsection{Monosaccharide analysis}

MAP and the reduced polysaccharide (MAP-R, $10 \mathrm{mg}$ each) were hydrolysed using $2 \mathrm{~N} \mathrm{H}_{2} \mathrm{SO}_{4}$ for $6 \mathrm{~h}$ with pinitol $(1 \mathrm{mg})$ as an internal standard. Alditol acetate as a standard monosaccharide and the sample were prepared by following the method by Jansson et al. ${ }^{42}$ and subjected to GLC analysis ${ }^{43}$ using an Agilent 7890B gas chromatograph equipped with a flame ionization detector (FID). The initial temperature of the column was $190{ }^{\circ} \mathrm{C}$ with a hold time of $1 \mathrm{~min}$; the temperature was increased at a rate of $3{ }^{\circ} \mathrm{C}$ per minute until attainment of the final temperature of $260{ }^{\circ} \mathrm{C}$, with holding for $10 \mathrm{~min}$. Helium was used as a carrier gas with a flow rate of $1.2 \mathrm{~mL} \mathrm{~min}^{-1}$. The monosaccharide composition (for neutral as well as acidic sugar residues) was calculated by comparing the GLC chromatograms of native and reduced polysaccharides.

The uronic acid was further quantified spectrophotometrically by the 3,5 -DMP method. ${ }^{44}$ All the experiments were performed in triplicate.

\subsection{Linkage analysis}

Linkage analysis of MAP was performed by methylation of the reduced and native polysaccharides with the modified Hakomori method and derivatization to PMAA, followed by comparing the GC-MS results. ${ }^{45}$ Briefly, the polysaccharide (50 $\mathrm{mg}$ ) was dissolved in DMSO (10 mL; dried over molecular sieves) in a stream of nitrogen. Alkoxide ions were formed by portionwise addition of sodium hydride at $60{ }^{\circ} \mathrm{C}$, and the reaction mixture was left for $1 \mathrm{~h}$ with continuous stirring. At this stage, the nitrogen flow was stopped and the reaction mixture was cooled over an ice bath followed by addition of methyl iodide. The permethylated polysaccharide was extracted with chloroform $(3 \times 10 \mathrm{~mL})$. The combined fractions were washed with distilled water, dried over anhydrous sodium sulphate and concentrated under vacuum.

The permethylated derivatives were hydrolysed with $90 \%$ (v/ v) formic acid $(5 \mathrm{~h})$ followed by hydrolysis with $2 \mathrm{M}$ TFA for $6 \mathrm{~h}$. The hydrolysates were reduced to alditols with sodium borohydride and converted to partially methylated alditol acetates (PMAA) using pyridine: acetic anhydride in a $1: 1$ ratio. The PMAAs were analyzed by GC-MS (Agilent 7890B gas chromatograph with a 5977A mass spectrometer with electron ionization (EI) and a quadrupole analyzer) using an RTX 2330 column and helium as a carrier gas. The program used to run the PMAA derivatives was as follows: the initial temperature of the column was $170{ }^{\circ} \mathrm{C}$, and the temperature was increased at a rate of $6{ }^{\circ} \mathrm{C}$ per minute up to $240{ }^{\circ} \mathrm{C}$ with final holding for $10 \mathrm{~min} .10 \mu \mathrm{L}$ of sample was injected with a split ratio of $10: 1$. The linkages were identified by the relative retention times and fragmentation patterns of the mass spectra for individual PMAA peaks.

\subsection{Partial hydrolysis and ESI-MS analysis}

MAP (5 mg) was partially hydrolysed using $0.5 \mathrm{M}$ and $1 \mathrm{M}$ hydrochloric acid $(5 \mathrm{~mL})$ for $1 \mathrm{~h}$ separately. The partially hydrolysed solution was dried under vacuum on a rotary evaporator. Traces of acid were removed by passing a stream of nitrogen. ESI-MS analysis was performed on a Waters Micromass Q-TOF micro instrument equipped with the Waters Alliance 2795 separations module in unit resolution (MRM) acquisition mode. The injection volume of analyte was $20 \mu \mathrm{L}$ and the flow rate was $0.4 \mathrm{~mL} \mathrm{~min}^{-1}$. MS was operated in positive and negative ionization mode, and the spectra were acquired with a $\mathrm{m} / \mathrm{z}$ range of 0 to 2000 . Other parameters used for the mass spectrometer were desolvation gas: $550 \mathrm{~L} \mathrm{~h}^{-1}$, cone gas: $30 \mathrm{~L} \mathrm{~h}^{-1}$, desolvation temperature: $300{ }^{\circ} \mathrm{C}$, source temperature: $110^{\circ} \mathrm{C}$. The capillary and cone voltages were set at $3000 \mathrm{~V}$ and $30 \mathrm{~V}$, respectively, and a collision energy of $4 \mathrm{eV}$ was used. $\mathrm{N}_{2}(6$ to 7 bar) and argon (5 to 6 bar) were used as drying gases.

\subsection{NMR spectral analysis}

MAP (35 mg) was deuterium-exchanged with $99.9 \% \mathrm{D}_{2} \mathrm{O}(3 \times$ $650 \mu \mathrm{L}$ ) three times using freeze-thaw cycles prior to NMR analysis. The deuterium-exchanged polysaccharide was dissolved in $\mathrm{D}_{2} \mathrm{O}(650 \mu \mathrm{L})$ and the spectra were recorded on a JEOL JNM-ECS400 spectrometer. The NMR measurements included 
various experiments, viz. ${ }^{1} \mathrm{H},{ }^{13} \mathrm{C}$, DEPT-135, COSY, HSQC and HMBC. The experiments were performed at $292 \mathrm{~K}$. The raw data were processed with Mestrec Nova version 9.0.0.

\subsection{Reducing power}

The reducing power of MAP was determined by the potassium ferricyanide assay according to the standard protocol. ${ }^{1}$ Briefly, $1 \mathrm{~mL}$ phosphate buffer $(0.2 \mathrm{M}, \mathrm{pH} 6.6)$ was added to $0.5 \mathrm{~mL}$ potassium ferricyanide $(1 \%, \mathrm{w} / \mathrm{v})$. To the above solution, $1 \mathrm{~mL}$ of sample solution (ascorbic acid and MAP) with varying concentration ( 0.2 to $1.8 \mathrm{mg} \mathrm{mL} \mathrm{m}^{-1}$, w/v in distilled water) was added. The resulting mixtures were incubated at $50{ }^{\circ} \mathrm{C}$ in a water bath for 20 minutes and cooled to ambient temperature. This was followed by addition of $1 \mathrm{~mL}$ trichloroacetic acid $(10 \%, \mathrm{w} / \mathrm{v})$ and $0.2 \mathrm{~mL}$ freshly prepared ferric chloride solution $(0.1 \%, \mathrm{w} / \mathrm{v})$. The final solution was vortexed, and the absorbance was measured at $700 \mathrm{~nm}$. The reducing power was calculated using the formula:

$$
\text { Reducing power }=\left[\mathrm{As}_{700}-\mathrm{Ac}_{700}\right]
$$

where $\mathrm{As}_{700}$ is the absorbance of the sample and $\mathrm{Ac}_{700}$ is the absorbance of a control in which $\mathrm{FeCl}_{3}$ solution was replaced by water.

\section{Results and discussion}

\subsection{Isolation of polysaccharide}

The alkali-soluble polysaccharide (MAP) was isolated in 1.15\% $(\mathrm{w} / \mathrm{w})$ yield. The ash content of MAP was $0.75 \%(\mathrm{w} / \mathrm{w})$ on a dry weight basis. The aqueous solution $(1 \%, w / v)$ of MAP has a $\mathrm{pH}$ value of 6.4 .

\subsection{GPC of MAP}

A graph of the fractions collected from GPC against absorbance was plotted using the anthrone-sulphuric acid method ${ }^{39}$ at $620 \mathrm{~nm}$, as shown in Fig. 1.
The fractions of the major eluted peaks (23-34) were collected and pooled, dialyzed against distilled water (48 h) and lyophilized to obtain the homogeneous polysaccharide (146 mg).

\subsection{Monosaccharide analysis}

Qualitative evaluation of MAP with paper chromatography indicated the presence of five neutral monosaccharides and one acidic sugar residue. The sugar residues identified in MAP were rhamnose (Rha), arabinose (Ara), xylose (Xyl), glucose (Glc), galactose (Gal), and glucuronic acid (GlcA). The monosaccharide composition of MAP was quantitatively investigated by GLC. Based on comparison with monosaccharide standards, MAP was found to be composed of xylose $(64.52 \mathrm{~mol} \%)$ and arabinose $(18.87 \mathrm{~mol} \%)$. The other sugar residues were found to be rhamnose, glucose, and galactose in 3.27, 3.25 and 10.09 mole percentages, respectively. After complete reduction with EDC, $\mathrm{HCl}$ and $\mathrm{NaBH}_{4}$, the carboxyl-reduced polysaccharide MAP-R was obtained. MAP-R was found to be composed of Rha, Ara, Xyl, Glc and Gal in 3.04, 18.36, 60.42, 8.97, 9.21 mole percentages, respectively. The mol\% of glucuronic acid was 5.76 based on the percentage increase of glucose in the reduced polysaccharide (MAP-R) vis-à-vis native MAP. The molar ratio of monosaccharides Rha, Ara, Xyl, Glc, Gal and GlcA in the alkali-soluble polysaccharide was $1.00: 6.04: 19.88: 1.07: 3.03: 1.95$. The arabinose/xylose ratio of MAP was found to be 0.3 .

The glucuronic acid content was analyzed using a spectrophotometric method based on the 3,5-dimethyl phenol assay. It was found to be $6.78 \%(\mathrm{w} / \mathrm{w}) \pm 0.51(\mathrm{avg} \pm \mathrm{st} \mathrm{dev})$ in MAP. ${ }^{44}$

\subsection{Linkage analysis}

The linkage pattern of MAP was revealed by complete methylation of native (MAP) and reduced (MAP-R) polysaccharides followed by hydrolysis, derivatisation to PMAA and GC-MS analysis, as explained in Section 2.6. The PMAAs were characterized by relative retention time and mass fragmentation pattern. The results of the

\section{Elution Pattern of MAP}

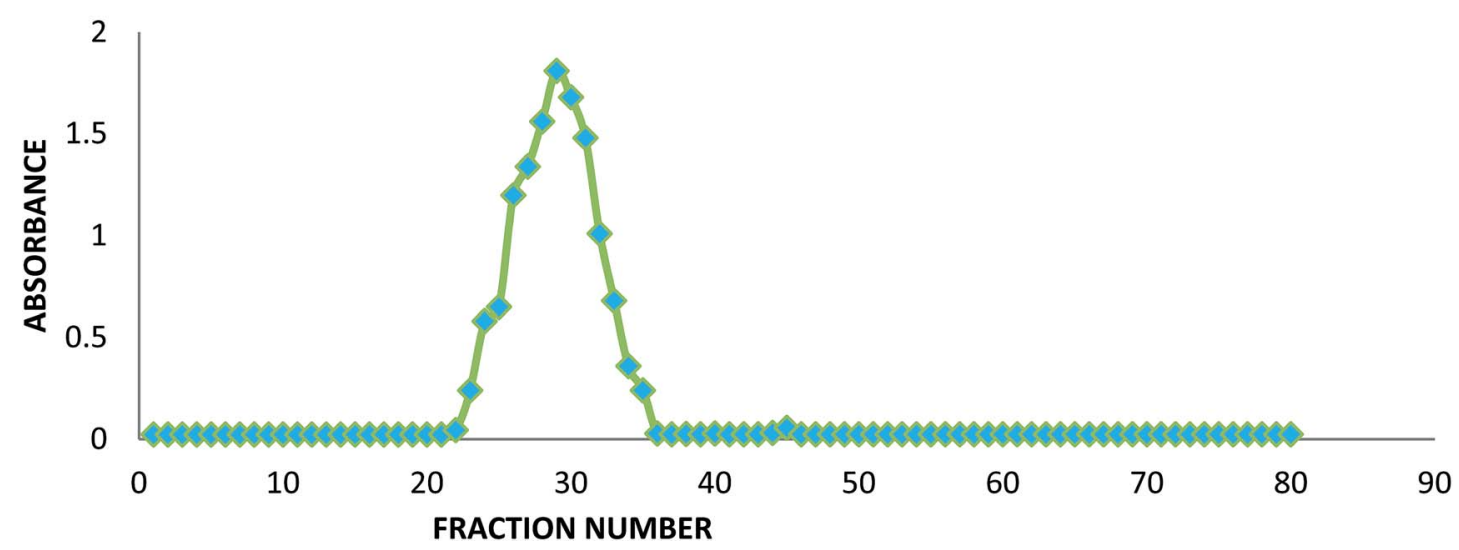

Fig. 1 Elution pattern of MAP in GPC. 
Table 1 Linkage analysis of MAP

\begin{tabular}{lllll}
\hline PMAA derivative & MAP $(\mathrm{mol} \%)$ & MAPR $(\mathrm{mol} \%)$ & Linkage identified & Observed mass fragments $(m / z)$ \\
\hline $1,5-\mathrm{Ac}_{2}-2,3,4-\mathrm{Me}_{3}$-rhamnitol & 3.23 & 3.13 & t-Rha & $43,59,87,99,89,101,117,131,161,175$ \\
$1,4-\mathrm{Ac}_{2}-2,3,5-\mathrm{Me}_{3}$-arabinitol & 3.35 & 3.19 & t-Ara & $43,45,59,87,101,117,129,145,161$ \\
$1,3,4-\mathrm{Ac}_{3}-2,5-\mathrm{Me}_{2}$-arabinitol & 16.19 & 15.21 & $1,3-\mathrm{Araf}$ & $43,59,71,87,99,101,117,129,173,205,233$ \\
$1,3,5-\mathrm{Ac}_{3}-2,4-\mathrm{Me}_{2}$-xylitol & 12.83 & 12.25 & $1,3-\mathrm{Xyl} p$ & $43,59,71,87,101,117,233$ \\
$1,4,5-\mathrm{Ac}_{3}-2,3-\mathrm{Me}_{2}$-xylitol & 32.26 & 30.09 & $1,4-\mathrm{Xyl} p$ & $43,59,71,87,99,101,117,129,161,189$ \\
$1,2,4,5-\mathrm{Ac}_{4}-3-\mathrm{Me}^{-x y l i t o l}$ & 19.35 & 17.96 & $1,2,4-\mathrm{Xyl} p$ & $43,74,87,101,129,145,161,189$, \\
$1,5-\mathrm{Ac}_{2}-2,3,4,6-\mathrm{Me}_{4}$-glucitol & - & 6.25 & t-GlcpA & $43,45,59,71,87,101,117,129,145,161,173,205$ \\
$1,4,5-\mathrm{Ac}_{3}-2,3,6-\mathrm{Me}_{3}$-galactitol & 9.68 & 8.99 & $1,4-\mathrm{Gal} p$ & $43,45,58,71,87,99,101,117,129,131,157,161,173,233$ \\
$1,4,5,6-\mathrm{Ac}_{4}-2,3-\mathrm{Me}_{2}$-glucitol & 3.11 & 2.93 & $1,4,6-\mathrm{Glc} p$ & $43,57,71,85,99,117,127,142,161,173,201,261$
\end{tabular}

methylation analysis of MAP are presented in Table 1. MAP was found to contain $32.26 \mathrm{~mol} \%$ 2,3-O-Me $-1,4,5-\mathrm{O}-\mathrm{Ac}_{3}$-pentitol and $19.35 \mathrm{~mol} \% 3-\mathrm{O}-\mathrm{Me}-1,2,4,5-\mathrm{O}-\mathrm{Ac}_{4}$-pentitol. According to the monosaccharide analysis, xylose is the most abundant sugar residue present in MAP, which indicates that 2,3-O- $\mathrm{Me}_{2}-1,4,5-\mathrm{O}-\mathrm{Ac}_{3}$-pentitol

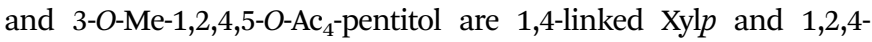
linked Xyl $p$, respectively; this was confirmed on the basis of the fragmentation pattern and relative retention times. According to the literature, both these linkages are assumed to be present in the backbone of xylan. ${ }^{46-48}$ Similarly, the other major linkages characterized in MAP were 16.19 mol\% 1,3-linked Araf, 12.83 mol\% 1,3linked Xyl $p$ and 9.68 mol\% 1,4-linked Gal $p$ with 3.11 mol\% 1,3,4linked Glcp; these probably form branches in MAP. The nonreducing terminal end linkages were found to be t-linked Rhap (3.23 $\mathrm{mol} \%$ ) and t-linked Araf (3.35 mol\%) in MAP. Methylation analysis of MAP-R (reduced MAP) showed t-linked Glcp at $6.25 \mathrm{~mol} \%$, suggesting that glucuronic acid is present as t-linked GlcpA in the polysaccharide. The excess percentage of xylose followed by arabinose when combined with the linkage results reveals the arabinoxylan nature of the polysaccharide. The methylation results are in agreement with the monosaccharide composition analysis.

\subsection{Partial hydrolysis and ESI-MS analysis}

MAP was partially hydrolysed using $0.5 \mathrm{M}$ and $1 \mathrm{M} \mathrm{HCl}$ to obtain a mixture of oligomers. Because the individual linkages between various monosaccharides were already identified by GC-MS investigation of the PMAA derivatives, ESI-MS $(n=1)$ of the partially degraded polysaccharide was performed to support the PMAA analysis and to establish the arrangement of monomer buildups in the oligomers to better understand the structure of the polysaccharide. The hydrolysed mixture was studied in positive as well as negative ion mode to obtain maximum information about the oligomeric pattern. Oligomers containing pentose (Pent), hexose (Hex), uronic acid (UA) and rhamnose (Rha) with DP7 to DP2 were identified in the mass spectrum. ESI-MS analysis revealed a pentose sugar with an anhydro mass unit of 132.0 to be the most abundant sugar residue in MAP.

The hydrolysate prepared using $0.5 \mathrm{M} \mathrm{HCl}$ furnished oligomers up to DP4 in positive ion mode (Fig. 2a). The ions of partial hydrolysates were obtained as sodium adducts of oligomers.
Two tetramers of $\left[\mathrm{Pent}_{3}+\mathrm{Hex}+\mathrm{Na}\right]^{+}$and $\left[\mathrm{Pent}_{4}+\mathrm{Na}\right]^{+}$at $\mathrm{m} / z$ 599.07 and 569.11, respectively, were identified. Three trimers of $\mathrm{m} / \mathrm{z} 497.19,437.24$ and 467.22 were attributed to sodium adducts of oligomers $\left[\text { Pent }+\mathrm{Hex}_{2}+\mathrm{Na}\right]^{+},\left[\mathrm{Pent}_{3}+\mathrm{Na}\right]^{+}$and $\left[\mathrm{Pent}_{2}+\mathrm{Hex}+\mathrm{Na}\right]^{+}$, respectively. The dimers with $\mathrm{m} / z$ 365.33, 335.33 , and 305.35 were recognized as $\left[\mathrm{Hex}_{2}+\mathrm{Na}\right]^{+}$, $[$Pent $+\mathrm{Hex}$ $+\mathrm{Na}]^{+}$and $\left[\text {Pent }_{2}+\mathrm{Na}\right]^{+}$, respectively.

The hydrolysate formed using $1 \mathrm{M} \mathrm{HCl}$ exhibited spectra with good intensity and an increase in the number of peaks (Fig. 2b). The oligomers up to DP7 were identified in positive ion mode as sodium adducts. The oligomers with higher DP (7 to 5) include two heptamers, $\left[\text { Pent }_{6}+\mathrm{UA}+\mathrm{Na}-18\right]^{+}(\mathrm{m} / \mathrm{z}$ 990.91) and $\left[\mathrm{Pent}_{7}+\mathrm{Na}-18\right]^{+}(\mathrm{m} / z$ 946.98); three hexamers, $\left[\text { Pent }_{3}+\mathrm{Hex}+\mathrm{UA}+\mathrm{Rham}+\mathrm{Na}-18\right]^{+}(\mathrm{m} / z$ 903.01 $),\left[\right.$ Pent $_{5}+\mathrm{UA}$ $+\mathrm{Na}-18]^{+}\left(\mathrm{m} / z\right.$ 859.04) and $\left[\mathrm{Pent}_{6}+\mathrm{Na}-18\right]^{+}(\mathrm{m} / z$ 815.09); and three pentamers, $\left[\text { Pent }_{2}+\mathrm{Hex}+\mathrm{UA}+\mathrm{Rham}+\mathrm{Na}-18\right]^{+}(\mathrm{m} / z$ 771.14), $\left[\text { Pent }_{4}+\mathrm{UA}+\mathrm{Na}-18\right]^{+}\left(\mathrm{m} / z\right.$ 727.19) and $\left[\mathrm{Pent}_{5}+\mathrm{Na}-\right.$ $18]^{+}(\mathrm{m} / \mathrm{z}$ 683.23). The identified oligomers with lower DP include five tetramers, five trimers and three dimers. The observed tetramers were $\left[\mathrm{Pent}_{4}+\mathrm{Na}\right]^{+}\left(m / z\right.$ 569.12); $\left[\mathrm{Pent}_{3}+\right.$ $\mathrm{Hex}+\mathrm{Na}]^{+}\left(m / z\right.$ 599.07); $[\mathrm{Pent}+\mathrm{Hex}+\mathrm{UA}+\mathrm{Rham}+\mathrm{Na}-18]^{+}$ $\left(\mathrm{m} / z\right.$ 639.26); $\left[\mathrm{Pent}_{3}+\mathrm{UA}+\mathrm{Na}-18\right]^{+}\left(\mathrm{m} / z\right.$ 595.29); and $\left[\mathrm{Pent}_{4}+\right.$ Na-18 $]^{+}(m / z 551.34)$. The ion fragments of trimers at $m / z$ $507.36,463.23,419.27,437.25$, and 467.23 were attributed to $[\mathrm{Hex}+\mathrm{UA}+\mathrm{Rham}+\mathrm{Na}-18]^{+},\left[\mathrm{Pent}_{2}+\mathrm{UA}+\mathrm{Na}-18\right]^{+},\left[\mathrm{Pent}_{3}+\right.$ $\mathrm{Na}-18]^{+},\left[\mathrm{Pent}_{3}+\mathrm{Na}\right]^{+}$, and $\left[\mathrm{Pent}_{2}+\mathrm{Hex}+\mathrm{Na}\right]^{+}$, respectively. The recognized dimers were characterized as $\left[\mathrm{Pent}_{2}+\mathrm{Na}-\right.$ $18]^{+},\left[\text {Pent }_{2}+\mathrm{Na}\right]^{+}$, and $[\text {Pent }+\mathrm{Hex}+\mathrm{Na}]^{+}$with $m / z$ 287.36, 305.35 and 335.34 , respectively.

ESI-MS in negative mode produced chlorine and hydrogen ion adducts of oligomers. Oligomers up to DP5 were found in the partial hydrolysate mixture obtained using $0.5 \mathrm{M} \mathrm{HCl}$ (Fig. 2c). The oligosaccharides at $\mathrm{m} / \mathrm{z}$ 735.08, 603.20, 471.31, 339.39, 449.3, 317.39 and 335.22 were identified as $\left[\right.$ Pent $_{4}+\mathrm{UA}+$ $\mathrm{Cl}-4 \mathrm{H}]^{-}$(pentamer); $\left[\text {Pent }_{3}+\mathrm{UA}+\mathrm{Cl}-4 \mathrm{H}\right]^{-}$(tetramer); $\left[\right.$Pent $_{2}+$ $\mathrm{UA}+\mathrm{Cl}-4 \mathrm{H}]^{-}$(trimer); $[\text {Pent }+\mathrm{UA}+\mathrm{Cl}-4 \mathrm{H}]^{-}$(dimer); $\left[\right.$Pent $_{3}+$ $\mathrm{Cl}^{-}$(trimer); $\left[\mathrm{Pent}_{3}+\mathrm{Cl}\right]^{-}$(dimer); and $[\text {Pent }+\mathrm{Hex}+\mathrm{Cl}]^{-}$ (dimer).

The hydrolysate obtained with $1 \mathrm{M} \mathrm{HCl}$ (Fig. 2d) produced intense peaks up to DP6 which include one hexamer $\left[\mathrm{Pent}_{5}+\right.$ $\mathrm{UA}+\mathrm{Cl}-4 \mathrm{H}]^{-}\left(\mathrm{m} / z\right.$ 866.93) ; four pentamers, $\left[\right.$ Pent $_{4}+\mathrm{Hex}+$ $\mathrm{Cl}]^{-}\left(\mathrm{m} / z\right.$ 743.05), $\left[\text { Pent }_{4}+\mathrm{UA}+\mathrm{Cl}-4 \mathrm{H}\right]^{-}\left(\mathrm{m} / z\right.$ 735.08), Pent $_{5}$ $+\mathrm{Cl}]^{-}\left(\mathrm{m} / \mathrm{z}\right.$ 713.06), and $\left[\mathrm{Pent}_{5}-\mathrm{H}\right]^{-}(\mathrm{m} / \mathrm{z}$ 677.13); four 

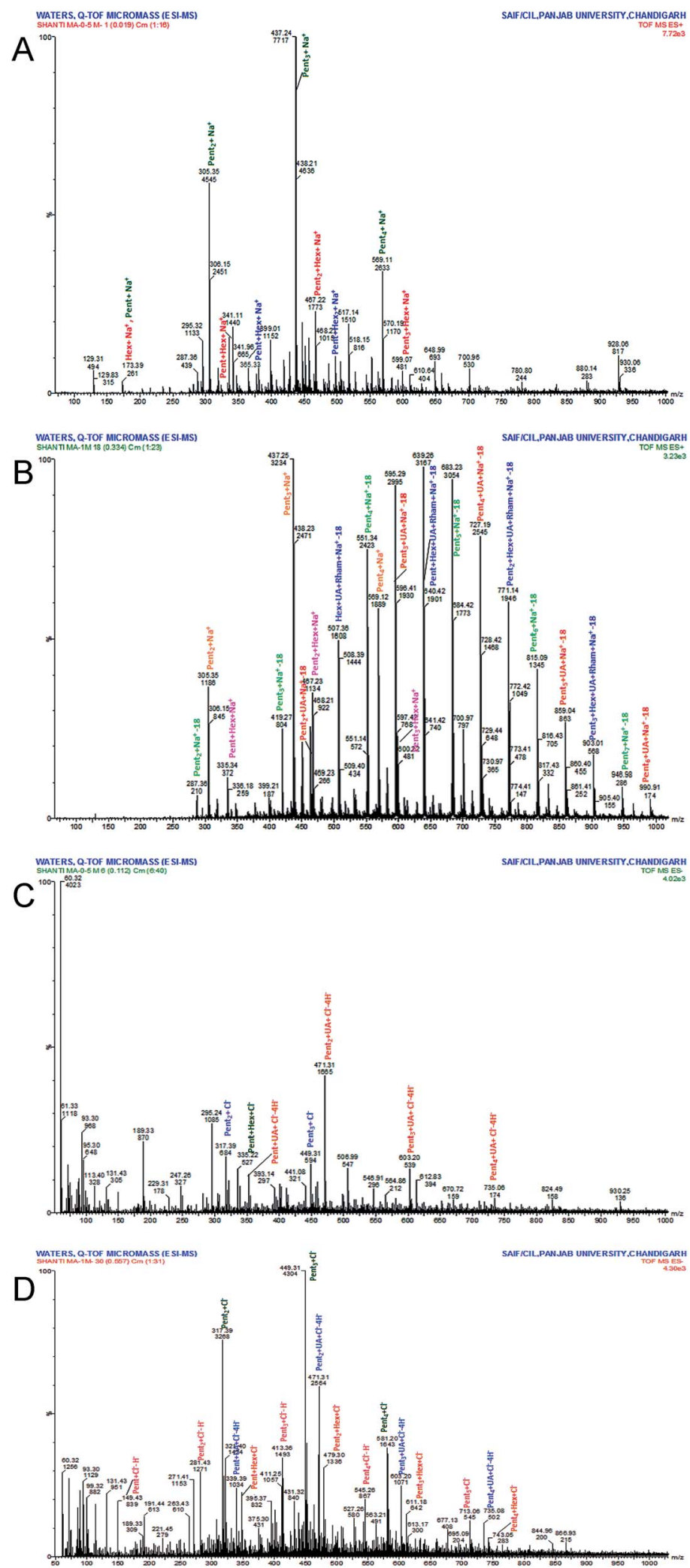

Fig. 2 (A) ESI+ve mode spectrum of MAP hydrolysate $(0.5 \mathrm{M} \mathrm{HCl})$, (B) ESI+ve mode spectrum of MAP hydrolysate (1 M HCl), (C) ESI-ve mode spectrum of MAP hydrolysate $(0.5 \mathrm{M} \mathrm{HCl})$, (D) ESI-ve mode spectrum of MAP hydrolysate $(1 \mathrm{M} \mathrm{HCl})$.

tetramers, $\left[\mathrm{Pent}_{3}+\mathrm{Hex}+\mathrm{Cl}\right]^{-}\left(m / z\right.$ 611.18), $\left[\mathrm{Pent}_{3}+\mathrm{UA}+\mathrm{Cl}-\right.$ $4 \mathrm{H}]^{-}\left(\mathrm{m} / z\right.$ 603.20), $\left[\text { Pent }_{4}+\mathrm{Cl}\right]^{-}\left(\mathrm{m} / z\right.$ 581.20), and $\left[\text { Pent }_{4}-\mathrm{H}\right]^{-}$ $\left(\mathrm{m} / z\right.$ 545.26); four trimers, $\left[\mathrm{Pent}_{2}+\mathrm{Hex}+\mathrm{Cl}\right]^{-}(\mathrm{m} / z$ 479.30), $\left[\text { Pent }_{2}+\mathrm{UA}+\mathrm{Cl}-4 \mathrm{H}\right]^{-}(\mathrm{m} / \mathrm{z}$ 471.31 $),\left[\text { Pent }_{3}+\mathrm{Cl}\right]^{-}(\mathrm{m} / \mathrm{z}$ 449.31), and $\left[\mathrm{Pent}_{3}-\mathrm{H}\right]^{-}(\mathrm{m} / z$ 413.36); and four dimers, [Pent $+\mathrm{Hex}+\mathrm{Cl}]^{-}(\mathrm{m} / \mathrm{z} 347.37),[\mathrm{Pent}+\mathrm{UA}+\mathrm{Cl}-4 \mathrm{H}]^{-}(\mathrm{m} / \mathrm{z} 339.39)$, 
Table 2 Oligomers of MAP identified in ESI+ve and ESI-ve modes; DP = degree of polymerization ( $n$ represents the number of pentoses in the oligomers)

DP

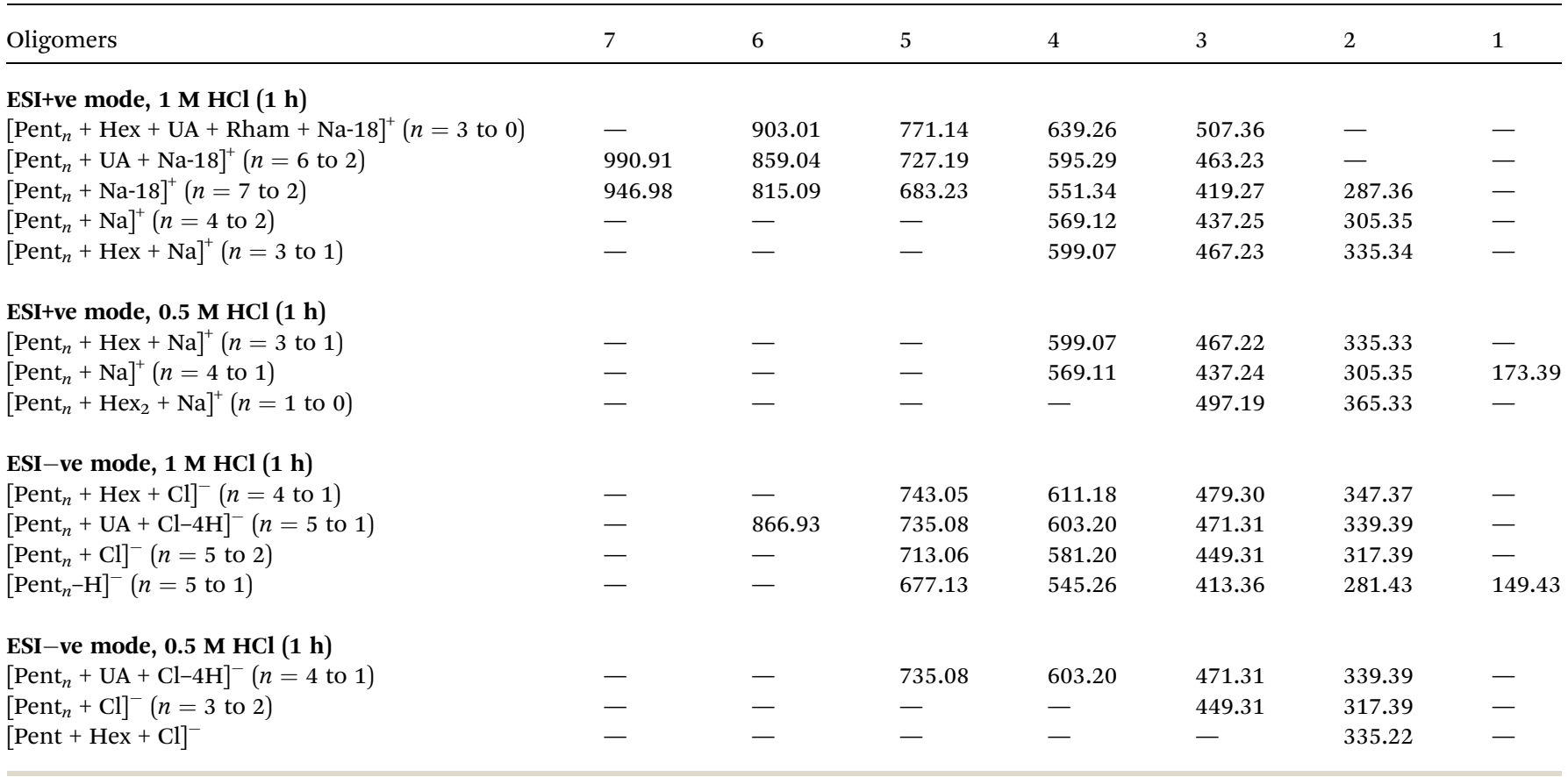

$\left[\text { Pent }_{2}+\mathrm{Cl}\right]^{-}(m / z 317.39)$, and $\left[\text { Pent }_{2}-\mathrm{H}\right]^{-}(\mathrm{m} / z$ 281.43). One monomer, [Pent-H] $]^{-}$, was observed at $m / z 149.43$.

The abundance of pentose-containing oligomers in the ESIMS spectra supported the monosaccharide and methylation results, which showed xylose (a pentose sugar) to be the most abundant residue in MAP. The complete oligomeric patterns identified are presented in Table 2.

\subsection{NMR analysis and structure of MAP}

NMR spectra of MAP were recorded on a JEOL JNM-ECS400 spectrometer. The completely deuterium-exchanged MAP (35 mg dissolved in $650 \mu \mathrm{L}$ of $\left.\mathrm{D}_{2} \mathrm{O}\right)$ was subjected to $1 \mathrm{D}\left({ }^{1} \mathrm{H},{ }^{13} \mathrm{C}\right.$, DEPT-135) and 2D (HSQC, HMBC, TOCSY, COSY) experiments to acquire significant information for the elucidation of the structure of MAP. The anomeric protons appeared between 4.20 and $5.20 \mathrm{ppm}$ in the ${ }^{1} \mathrm{H}$ NMR spectrum at 5.01, 4.90, 4.59, 4.83, 4.44, 4.29, 4.23, 5.11, 4.39 and 5.05 ppm (Fig. 3a). In the ${ }^{1} \mathrm{H}$ NMR spectrum, one signal was found at $1.01 \mathrm{ppm}$ which was highly shielded; this was assigned to the methyl protons of rhamnose residues. The ${ }^{13} \mathrm{C}$ NMR spectrum (Fig. 3b) showed ten anomeric carbon signals at 107.48, 107.24, 104.03, 101.62, 101.47, 101.68, 101.67, 97.44, 96.39, and 91.91 ppm; these are labeled as A, B, C, D, E, F, G, H, I and J, respectively. The corresponding anomeric proton signals in the ${ }^{1} \mathrm{H}$ NMR spectrum were marked with the contribution of HSQC. The signal at $16.49 \mathrm{ppm}$ was assigned to the methyl carbon of rhamnose, and the signal at $174.75 \mathrm{ppm}$ was assigned to C-6 of GlcpA. All ${ }^{1} \mathrm{H}$ and ${ }^{13} \mathrm{C}$ NMR assignments were marked with the assistance of COSY, HSQC, HMBC and TOCSY [Fig. 3c-e] spectra. The chemical shifts of all the residues of MAP were assigned completely and are shown in Table 3.

Residue A showed an anomeric carbon chemical shift at $107.24 \mathrm{ppm}$, and its anomeric proton shift was observed at $5.01 \mathrm{ppm}$. Other proton chemical shifts were assigned from the COSY and TOCSY spectra. The other carbon signals of residue A were observed at 76.10, 80.74, 80.67 and 60.65, corresponding to C-2, C-3, C-4 and C-5, respectively. The intensity of the anomeric carbon chemical shift is weaker and was assigned to $\alpha$-linked $\operatorname{Ara} f(1 \rightarrow$; this is supported by the methylation results, which show a lower percentage of $\alpha$-linked Araf $(1 \rightarrow$ compared to $\rightarrow 3)$ $\alpha$-linked Araf $(1 \rightarrow$. The proton and carbon chemical shifts were in agreement with literature values. ${ }^{46,48-50}$

Residue B showed a carbon chemical shift at $107.48 \mathrm{ppm}$ with a proton shift at $4.90 \mathrm{ppm}$. The C-3 chemical shift is also deshielded, with a chemical shift value of $83.75 \mathrm{ppm}$. Methylation analysis showed that the percentage of $\rightarrow 3$ )- $\alpha$-linked $\operatorname{Ara} f(1 \rightarrow$ is much higher than that of $\alpha$-linked Araf $(1 \rightarrow$. The anomeric signal for residue $\mathrm{B}$ is more intense than that for residue $\mathrm{A}$ in the HSQC spectrum. All these factors suggest that this residue is $\rightarrow 3)$ - $\alpha$-linked $\operatorname{Ara} f(1 \rightarrow$. The carbon signals of residue $\mathrm{B}$ were observed at $76.45,80.93$, and 58.31 , corresponding to C-2, C-4 and C-5 from the HSQC spectrum. These assignments were consistent with previous data. ${ }^{\mathbf{4 8 , 4 9}}$

Residue $\mathrm{C}$ showed anomeric carbon and proton chemical shifts at 104.03 and $4.59 \mathrm{ppm}$, respectively. Its anomeric proton chemical shift indicates that it is $\beta$-linked. According to methylation fragmentation analysis and comparison of the NMR data, residue $\mathrm{C}$ was assigned as $\rightarrow 4)$ - $\beta$-linked Gal $p(1 \rightarrow$, which was found to be consistent with the literature. ${ }^{51}$ The other 
carbon chemical shifts were 70.92, 72.09, 68.78, 72.26 and 66.18, which correspond to C-2, C-3, C-4, C-5 and C-6, respectively.

The anomeric carbon chemical shift of residue D was found at $101.62 \mathrm{ppm}$, with the anomeric proton chemical shift at $4.83 \mathrm{ppm}$. The chemical shifts of other protons were assigned through COSY, and the corresponding carbon shift values were recognized with HSQC. The chemical shift values of the other carbons were found at 68.78, 70.70, 73.38, 71.81 and $16.49 \mathrm{ppm}$ and were assigned to C-2, C-3, C-4, C-5 and C-6, respectively. The NMR data was in agreement with literature data. ${ }^{49}$ The spectral assignments and methylation results indicate that residue $\mathrm{D}$ is $\alpha$-linked Rhap $(1 \rightarrow$.

Residues E, F and G showed anomeric carbon/proton shift values at $101.47 / 4.44,101.68 / 4.29$, and $101.67 / 4.23 \mathrm{ppm}$, respectively. $\rightarrow 4)$ - $\beta$-linked Xyl $p(1 \rightarrow, \rightarrow 2,4)$ - $\beta$-linked Xyl $p(1 \rightarrow$ and $\rightarrow 3)$ - $\beta$-linked $\mathrm{Xyl} p(1 \rightarrow$ are the most abundant linkages found in the methylation study, and they were found to be $32.26,19.35$ and $12.83 \mathrm{~mol} \%$, respectively. The anomeric carbon and proton intensities of residues $\mathrm{E}, \mathrm{F}$ and $\mathrm{G}$ were found to be the most abundant peaks in the spectra. The carbon chemical shift C-3 (81.02 ppm) of residue E was found to be deshielded, and C-4 (75.99 ppm) of residue F was also deshielded. Similarly, C-2 (74.49 ppm) and C-4 (81.02 ppm) of residue G showed deshielding. The chemical shifts of C-2, C-4, and C-5 of residue E were observed at 75.38, 81.02 and 63.63 ppm, respectively. The chemical shifts of C-2, C-3 and C-5 of residue F were observed at $72.38,74.49$, and $62.48 \mathrm{ppm}$, respectively. The chemical shifts of C-3 and C-5 of residue $\mathrm{G}$ were observed at 77.21 and $62.49 \mathrm{ppm}$, respectively. The spectral assignments and methylation results
A

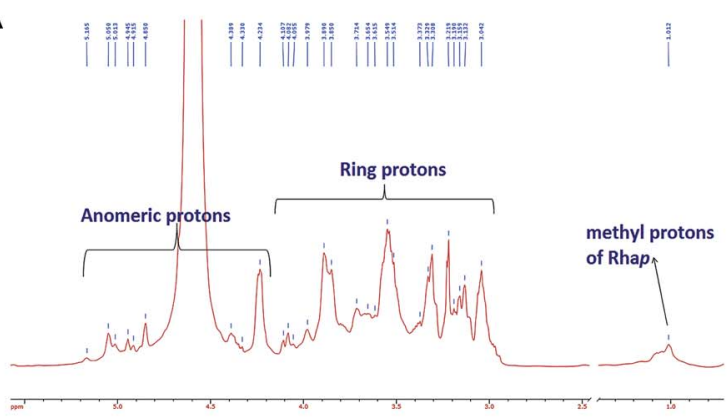

C

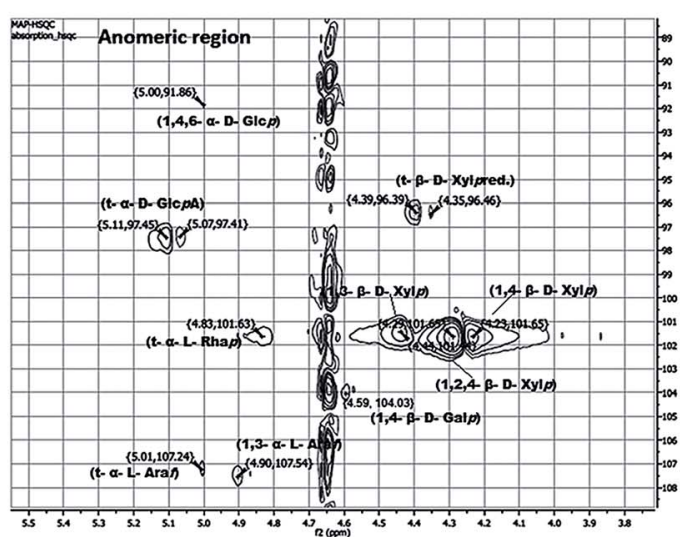

$\mathrm{E}$

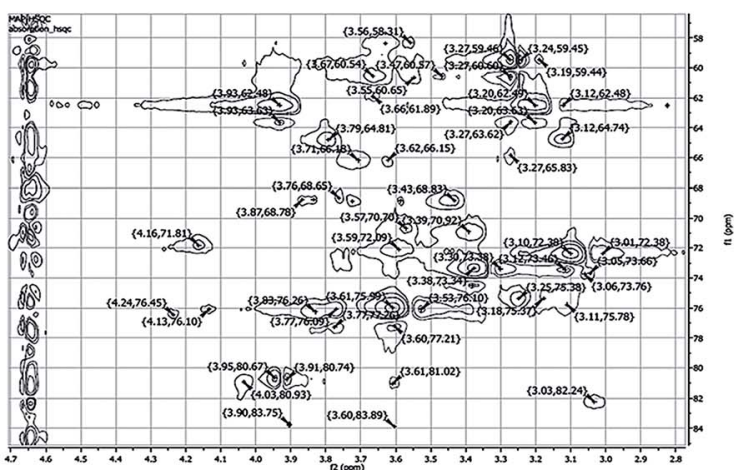

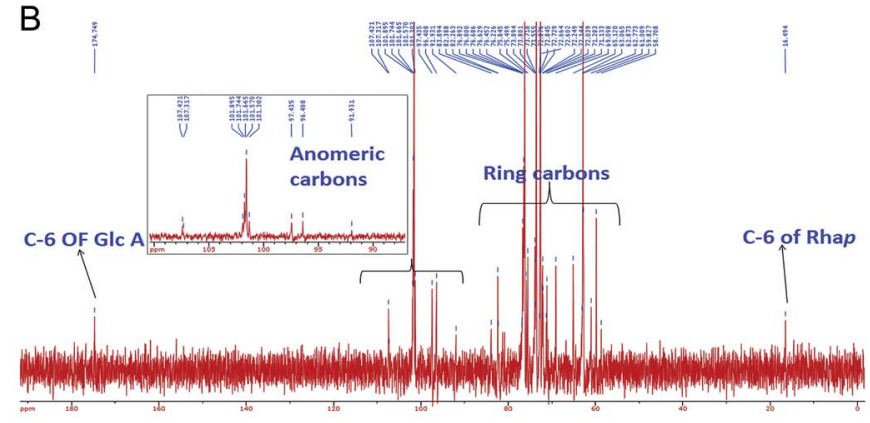

D

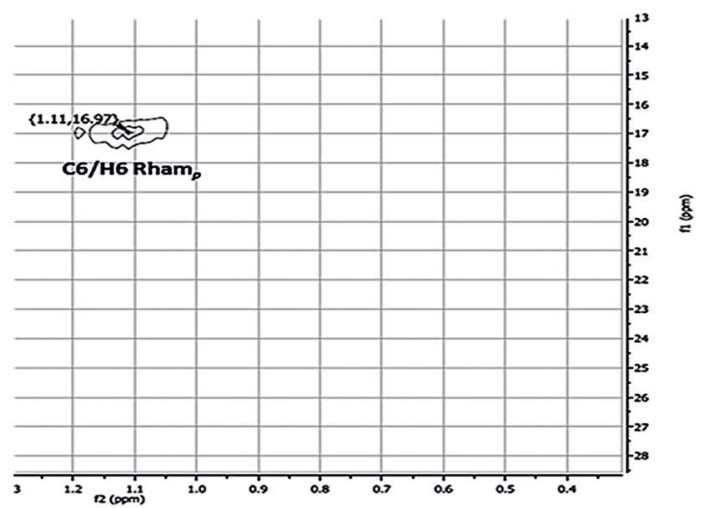

$\mathrm{F}$

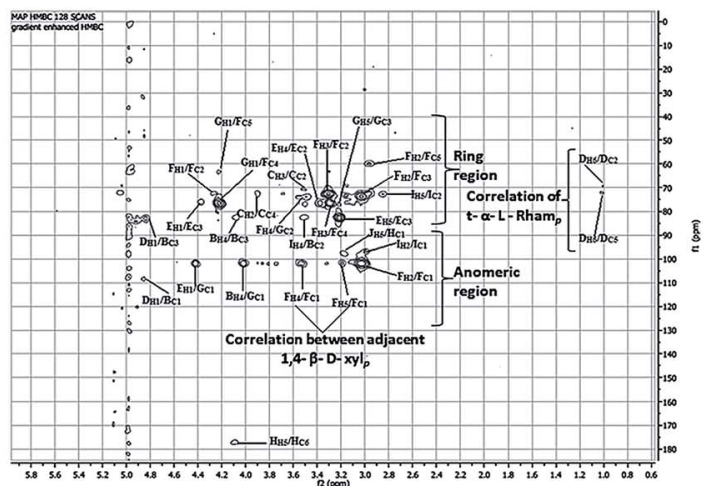

Fig. 3 (A) ${ }^{1} \mathrm{H}$ NMR spectrum of MAP, (B) ${ }^{13} \mathrm{C}$ NMR spectrum of MAP, (C) HSQC spectrum of the anomeric region, (D) HSQC spectrum of the rhamnose region, (E) HSQC spectrum of the ring region, (F) HMBC spectrum with inter and intra-residue connectivities. 
revealed residues $\mathrm{E}, \mathrm{F}$, and $\mathrm{G}$ to be $\rightarrow 3)$ - $\beta$-linked Xyl $p(1 \rightarrow, \rightarrow 4)$ $\beta$-linked $\operatorname{Xyl} p(1 \rightarrow$ and $\rightarrow 2,4)$ - $\beta$-linked $\operatorname{Xyl} p(1 \rightarrow$. The other proton and carbon chemical shifts were assigned completely from the HSQC, COSY and TOCSY spectra, and the values were found to be in agreement with literature data. ${ }^{\mathbf{4 8 , 5 0 , 5 2 , 5 3}}$

The anomeric carbon signal of residue $\mathrm{H}$ was found at 97.44 ppm, and the anomeric proton shift was $5.11 \mathrm{ppm}$. The C-6 of residue $\mathrm{H}$ was found at $\mathbf{1 7 4 . 7 5} \mathrm{ppm}$, which is highly deshielded due to the carboxylic group of uronic acid. Other carbon signals were found at 70.92, 73.34, 80.74 and $71.81 \mathrm{ppm}$ and were assigned to C$2, \mathrm{C}-3, \mathrm{C}-4$ and C-5, respectively. These values were assigned to $\beta$ linked GlcpA(1 $\rightarrow$ and compared with the literature. ${ }^{54,55}$ Sometimes, GlcpA is also found in C-6 methyl ester form; however, in the present case, uronic acid was not methyl-esterified because no signal was found near $53 \mathrm{ppm}$ for the -OMe carbon. ${ }^{48,56}$ Also, no ester carbonyl peak was found in the FT-IR spectra, confirming that the GlcpA present in MAP is not methyl esterified.

Residue I showed anomeric C1/H1 chemical shifts at 96.39/ $4.39 \mathrm{ppm}$ with significant intensity. The other proton and carbon shift values were assigned with the aid of the COSY and HSQC spectra. The carbon chemical shift values at 72.76, 73.38, 76.10, and 59.45 ppm were assigned to C-2, C-3, C-4 and C-5, respectively. In conformity with the literature, ${ }^{57,58}$ the anomeric chemical shift value was found to be consistent with $\beta$-linked $\mathrm{Xyl} p(1 \rightarrow$ with a free reducing end, which is well reported in xylans from different plant sources. No evidence was found regarding $\beta$-linked $\operatorname{Xyl} p(1 \rightarrow$ residue in the methylation analysis; however, based on the NMR analysis, residue I was assigned to $\beta$-linked $\mathrm{Xyl} p(1 \rightarrow$ with a free reducing end.

Residue J showed anomeric C1/H1 chemical shifts at 91.91/ $5.05 \mathrm{ppm}$ with weak intensity. The other carbon signals of residue $\mathrm{J}$ were observed at 70.92, 72.09, 75.99, 65.62 and
58.31 ppm for C-2, C-3, C-4, C-5 and C-6, respectively. All the ${ }^{1} \mathrm{H}$ and ${ }^{13} \mathrm{C}$ chemical shift assignments of residue $\mathrm{J}$ were achieved using the COSY and HSQC spectra. Compared with previous reports $^{59}$ on methylation data and NMR peak intensity, residue J was assigned to $\rightarrow 4,6)$ - $\beta$-linked Glc $p(1 \rightarrow$.

The sequence of glycosyl residues in MAP was determined with the assistance of long-range HMBC coupling, as shown in Fig. 3f. The cross peaks of both anomeric carbons and the protons of the glycosyl residues were examined for both intra- and inter-residual connectivity. Cross-peaks were found between $\mathrm{H}-1$ (5.01 ppm) of residue A and C-1 $(107.48 \mathrm{ppm})$ of residue $\mathrm{B}$, representing $\rightarrow 3)$ - $\alpha$-linked $\operatorname{Ara} f(1 \rightarrow$ residues linked to O- 1 of $\alpha$-linked Ara $f(1 \rightarrow$. Crosspeaks were found between $\mathrm{H}-1$ (4.23 ppm) of residue $\mathrm{E}$ and C-1 (101.67 ppm) of residue $\mathrm{G}$, which indicates that the $\rightarrow 3$ )$\beta$-linked $\mathrm{Xyl} p(1 \rightarrow$ residues are linked to $\mathrm{O}-2$ of $\rightarrow 2,4)-\beta$ linked $\mathrm{Xyl} p(1 \rightarrow$. There were cross connections of $\mathrm{H}-1$ (4.23 ppm) of residue $\mathrm{G}$ with $\mathrm{C}-4$ and $\mathrm{C}-5$ of residue $\mathrm{F}$, showing that $\rightarrow 2,4)$ - $\beta$-linked $\mathrm{Xyl} p(1 \rightarrow$ is connected with $\rightarrow 4)$ - $\beta$ linked $\operatorname{Xyl} p(1 \rightarrow$. The methylation results show that $\rightarrow 4)-\beta$ linked $\operatorname{Xyl} p(1 \rightarrow$ is the most abundant linkage in MAP; this was further supported by the HMBC spectra because the cross peak intensity for $\rightarrow 4)$ - $\beta$-linked $\mathrm{Xyl} p(1 \rightarrow$ residues in HMBC is the maximum. Also, HMBC showed the greatest number of cross connecting linkages for $\rightarrow 4$ )- $\beta$-linked $\mathrm{Xyl} p(1 \rightarrow$. The inter-connections between $\rightarrow 4)$ - $\beta$-linked $\mathrm{Xyl} p(1 \rightarrow$ residues were found to be $\mathrm{H}-4$ (3.06 ppm) with $\mathrm{C}-1$ (101.68 ppm) and H-5 (3.93 ppm) with C-1 (101.68 ppm), indicating connections between $\rightarrow 4)$ - $\beta$-linked $\operatorname{Xyl} p(1 \rightarrow$. The cross connection of $\mathrm{H}-4$ (3.06 ppm) of residue I with $\mathrm{C}-3$ $(73.38 \mathrm{ppm})$ of residue $\mathrm{B}$ indicates that $\beta$-linked $\mathrm{Xyl} p(1 \rightarrow$ is connected to O-3 of $\rightarrow 3)$ - $\alpha$-linked Araf $(1 \rightarrow$. Intra-residual

Table 3 HSQC table for MAP

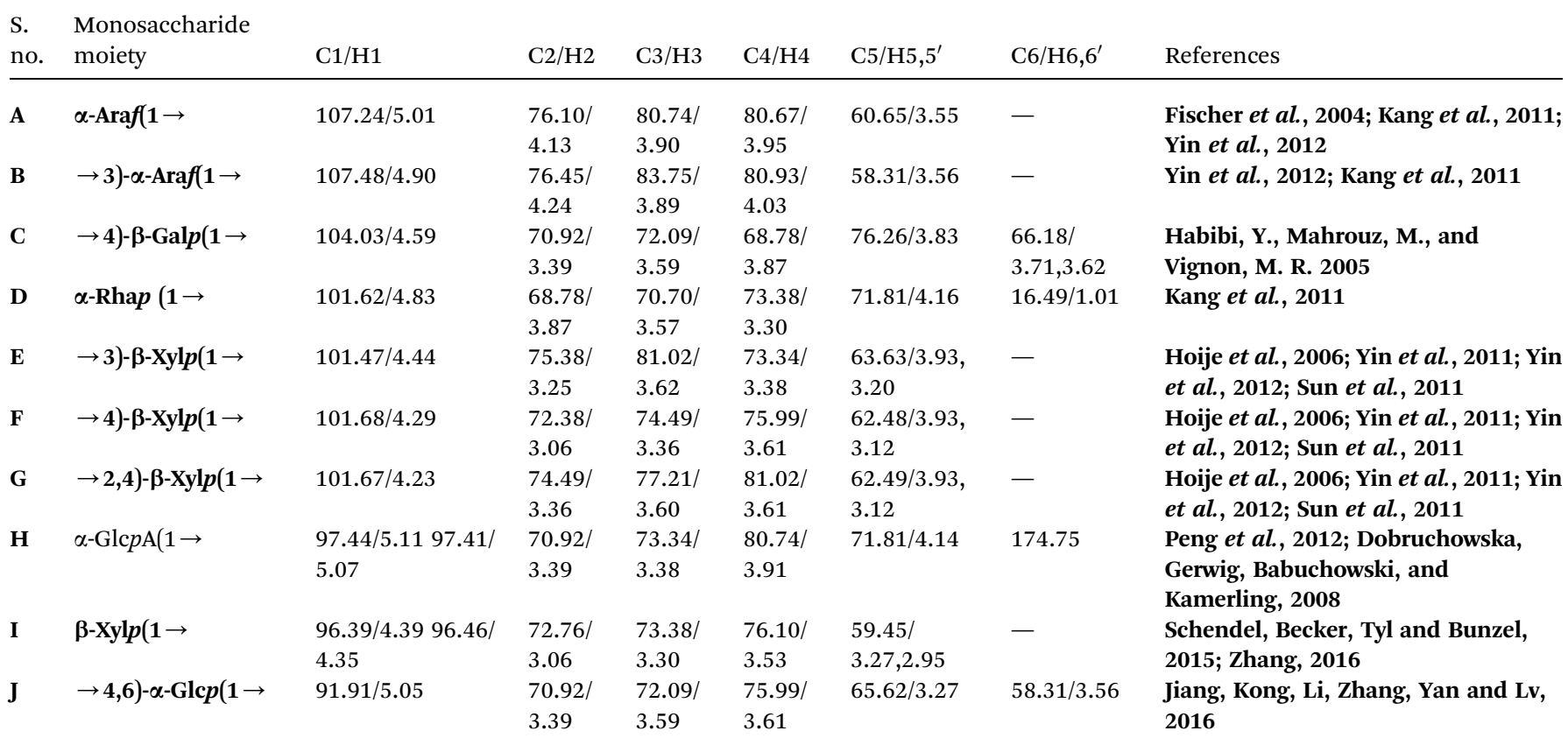


connectivities were found for residue $\mathrm{F} \rightarrow 4)$ - $\beta$-linked $\mathrm{Xyl} p(1 \rightarrow$ at $\mathrm{H}-1$ (3.06 ppm)/C-2 (72.38 ppm); H-3 (3.36 ppm)/ C-4 (75.99 ppm); C-2 (72.38 ppm); H-2 (3.61 ppm)/C-5 (62.48 ppm); C-1 (101.68 ppm); and C-3 (74.49 ppm). Other intraresidual connectivities observed for residue $H$ were $\alpha$ linked GlcpA $(1 \rightarrow$ at $\mathrm{H}-5 / \mathrm{C}-6$; for residue I, $\beta$-linked $\mathrm{Xyl} p(1 \rightarrow$ at $\mathrm{H}-2 / \mathrm{C}-1$ and $\mathrm{H}-5 / \mathrm{C}-2$; and for residue $\mathrm{J}, \rightarrow 4,6) \alpha-$ linked Glc $p(1 \rightarrow$ at $\mathrm{H}-5 / \mathrm{C}-1$. All the HMBC connectivities are summarized in Table 4.

Summarizing the linkage results and the NMR and partial acid hydrolytic analysis, a tentative structure (Fig. 5) is proposed for alkali-soluble polysaccharide MAP isolated from the leaves of $M$. coromandelianum. MAP was found to comprise a backbone of $\rightarrow 4$ )$\beta$-linked Xyl $p(1 \rightarrow$ with branching at O-2 mostly by $\rightarrow 3)$ - $\alpha$-linked $\operatorname{Ara} f(1 \rightarrow$ and $\rightarrow 3)-\beta$-linked Xyl $p(1 \rightarrow$ with a few residues of $\rightarrow 4)-\beta$ linked Gal $p(1 \rightarrow$. The structure was found to be similar to that of arabinoxylans. It is presumed that $\rightarrow 3)$ - $\alpha$-linked Araf $(1 \rightarrow$ and $\alpha$ linked Araf $(1 \rightarrow$ are present in the L-configuration of MAP and $\rightarrow 3)$ $\beta$-linked $\operatorname{Xyl} p(1 \rightarrow, \rightarrow 4)-\beta$-linked $\mathrm{Xyl} p(1 \rightarrow$ and $\rightarrow 2,4)$ - $\beta$-linked $\mathrm{Xyl} p(1 \rightarrow$ are present in its D-configuration because similar linkages have been reported in the literature for plant-based arabinoxylantype polysaccharides. ${ }^{60,61}$

\subsection{Reducing power of MAP}

MAP was analyzed for its ferric ion reducing ability using the potassium ferricyanide assay. ${ }^{1}$ Solutions of MAP and standard ascorbic acid were prepared in five concentrations, viz. 0.2, 0.6, $1.0,1.4$, and $1.8 \mathrm{mg} \mathrm{mL}^{-1}$. Both MAP and the standard showed dose-dependent behavior and increased reducing ability with increasing concentration of the sample. MAP and the standard

Table 4 HMBC correlation table for MAP

\begin{tabular}{|c|c|c|c|c|}
\hline \multirow[b]{2}{*}{ Residue } & \multirow[b]{2}{*}{ Linkage } & \multicolumn{3}{|c|}{ Observed Connectivities } \\
\hline & & Proton (ppm) & Residue & Carbon \\
\hline $\mathbf{A}$ & $\alpha-\operatorname{Araf}(1 \rightarrow$ & $\mathrm{H}-1(5.01)$ & B & $\mathrm{C}-1$ \\
\hline \multirow[t]{2}{*}{ B } & $\rightarrow 3)-\alpha-\operatorname{Ara} f(1 \rightarrow$ & $\mathrm{H}-4(4.03)$ & B & $\mathrm{C}-3$ \\
\hline & & & G & $\mathrm{C}-1$ \\
\hline \multirow[t]{2}{*}{ C } & $\rightarrow 4)-\beta-G a l p(1 \rightarrow$ & $\mathrm{H}-2(3.39)$ & $\mathrm{C}$ & $\mathrm{C}-4$ \\
\hline & & $\mathrm{H}-3$ (3.59) & $\mathrm{C}$ & C-2 \\
\hline \multirow[t]{2}{*}{ D } & $\alpha$-Rhap $(1 \rightarrow$ & $\mathrm{H}-1(4.83)$ & $\mathrm{D}$ & $\mathrm{C}-5$ \\
\hline & & $\mathrm{H}-5(4.16)$ & $\mathrm{D}$ & $\mathrm{C}-2$ \\
\hline \multirow[t]{4}{*}{$\mathbf{E}$} & $\rightarrow 3)-\beta-X y l p(1 \rightarrow$ & $\mathrm{H}-1(4.44)$ & $\mathrm{E}$ & $\mathrm{C}-3$ \\
\hline & & & $\mathrm{G}$ & $\mathrm{C}-1$ \\
\hline & & $\mathrm{H}-4(3.38)$ & $\mathrm{E}$ & $\mathrm{C}-2$ \\
\hline & & $\mathrm{H}-5(4.14)$ & $\mathrm{E}$ & $\mathrm{C}-3$ \\
\hline \multirow[t]{6}{*}{$\mathbf{F}$} & $\rightarrow 4)-\beta-X y l p(1 \rightarrow$ & $\mathrm{H}-1(4.29)$ & $\mathrm{F}$ & $\mathrm{C}-2$ \\
\hline & & $\mathrm{H}-2(3.06)$ & $\mathrm{F}$ & $\mathrm{C}-1, \mathrm{C}-3, \mathrm{C}-5$ \\
\hline & & $\mathrm{H}-3(3.36)$ & $\mathrm{F}$ & $\mathrm{C}-2, \mathrm{C}-4$ \\
\hline & & $\mathrm{H}-4(3.61)$ & $\mathrm{F}$ & $\mathrm{C}-1$ \\
\hline & & & G & $\mathrm{C}-2$ \\
\hline & & $\mathrm{H}-5$ (3.93) & $\mathrm{F}$ & $\mathrm{C}-1$ \\
\hline \multirow[t]{2}{*}{ G } & $\rightarrow 2,4)-\beta-\operatorname{Xyl} p(1 \rightarrow$ & $\mathrm{H}-1(4.23)$ & $\mathrm{F}$ & C-4, C-5 \\
\hline & & $\mathrm{H}-5(3.93)$ & G & $\mathrm{C}-3$ \\
\hline $\mathbf{H}$ & $\alpha-\operatorname{Glcp} \mathrm{A}(1 \rightarrow$ & $\mathrm{H}-5(4.14)$ & $\mathrm{H}$ & C-6 \\
\hline \multirow[t]{2}{*}{$\mathbf{I}$} & $\beta-X y l p(1 \rightarrow$ & $\mathrm{H}-2(3.06)$ & I & $\mathrm{C}-1$ \\
\hline & & $\mathrm{H}-4(3.53)$ & B & $\mathrm{C}-2$ \\
\hline $\mathbf{J}$ & $\rightarrow 4,6)-\alpha-\operatorname{Glcp}(1 \rightarrow$ & $\mathrm{H}-5(3.27)$ & $\mathrm{H}$ & $\mathrm{C}-1$ \\
\hline
\end{tabular}

showed ferric ion reducing powers of $0.914 \pm 0.01\left(R^{2}=0.972, p\right.$ $<0.05)$ and $2.178 \pm 0.004\left(R^{2}=0.730\right)$, respectively, at $1 \mathrm{mg}$ $\mathrm{mL}^{-1}$ concentration, as shown in Fig. 4 .

The antioxidant activities of carbohydrates, including monosaccharides, oligosaccharides and polysaccharides, have been discussed and validated by different researchers. Nishizawa et al. ${ }^{62}$ determined the abilities of galactinol and raffinose to scavenge hydroxyl radicals in vitro. It was observed that the second-order rate constants for the reactions between galactinol or raffinose and hydroxyl radicals were higher than those reported for typical antioxidants, such as ascorbate and reduced glutathione or citrulline. The studies concluded that galactinol and raffinose scavenge hydroxyl radicals as a novel function to protect plant cells from oxidative damage caused by methyl viologen treatment, salinity, chilling or drought. In another study, while comparing the antioxidant activities of monosaccharides and disaccharides, Morell et al. ${ }^{63}$ observed that the free radical scavenging activity of disaccharides, viz. maltose and sucrose, was greater than that of deoxyribose. It was proposed that the difference between the free radical scavenging activities and stabilities of disaccharides and monosaccharides is due to the variation in the number of hydroxyl residues, which are essential for $\mathrm{HO}^{*}$ (hydroxyl radical) quenching. Wehmeier and Mooradian ${ }^{64}$ reported that the antioxidant potency of deoxyribose was comparable to that of ascorbate using the 2,2-azobis(2-amidinopropane) dihydrochloride (AAPH) assay. Further, it was suggested that because glucose and ascorbate are highly similar in their molecular structures and share identical transporters, glucose and other related molecules can act as antioxidants under certain conditions. Van den et $a l .{ }^{65}$ reported that sucrose and sucrosyl oligosaccharides (SOS), including fructans and raffinose family oligosaccahrides (RFOs), fulfill various functional roles in plant metabolism. SOS may either directly detoxify ROS in chloroplasts and vacuoles or indirectly stimulate the classic antioxidative defense system. The in vitro antioxidant studies of polysaccharides also indicate that they are effective antioxidants. ${ }^{66}$ However, the underlying mechanism is still being investigated because the relationships between antioxidant activity and physicochemical properties or structural features are very complex and therefore have not been comprehensively elucidated and confirmed. ${ }^{67-69}$ The main physicochemical properties which determine the antioxidant activity of polysaccharides are dependent upon the monosaccharides constituting the main backbone and side chains as well as their linkages, functional groups, molecular weights, water solubility, degrees of branching, triple helical structures, etc. ${ }^{\mathbf{6 8 , 7 0 - 7 5}}$ It was also observed that the free radical scavenging activity increased when the monosaccharides were arrayed in polymeric form. ${ }^{76} \mathrm{~A}$ number of researchers reported that the structural properties of polysaccharides may affect the complex interactions of monosaccharides in polysaccharides to improve their hydrogen atomdonating capability, which in turn plays an important role in their antioxidant activity. ${ }^{71,77,78}$ In continuum, other researchers reported that the antioxidant activity of polysaccharides increases with increasing uronic acid content, which is due to the capability of uronic acids to chelate metal ions and in turn 


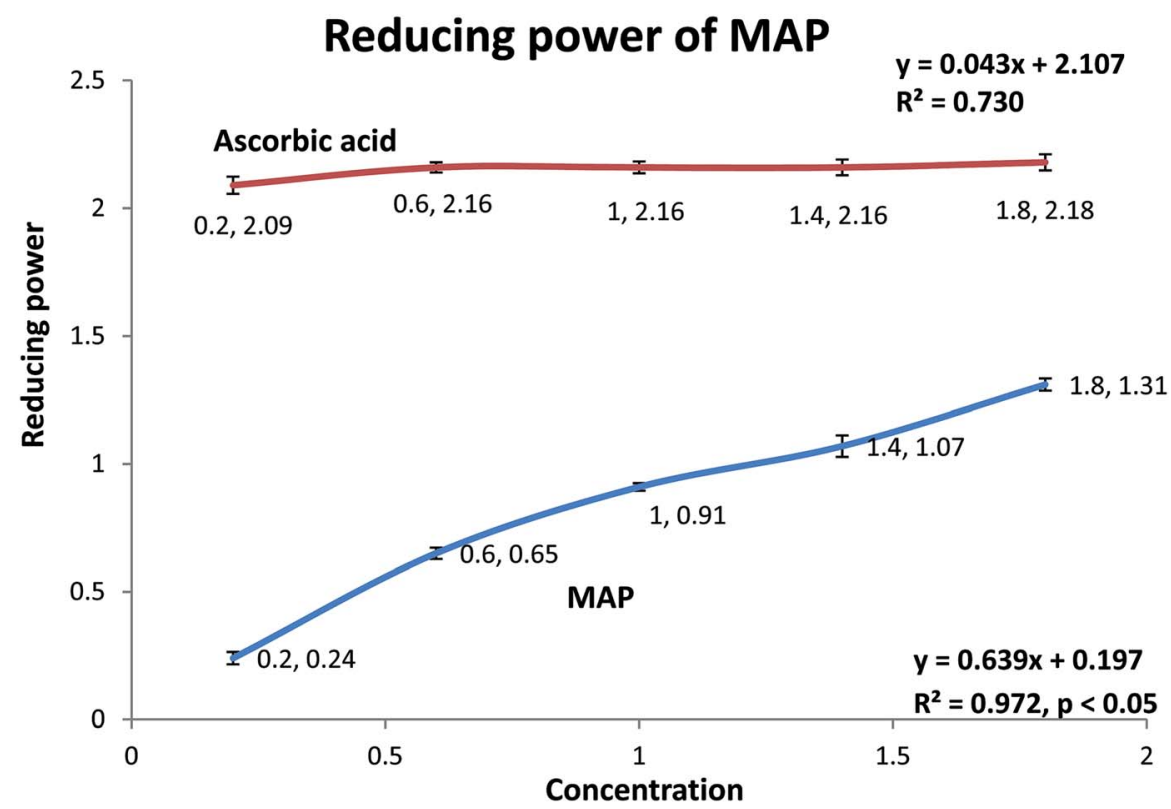

Fig. 4 Reducing power of $\operatorname{MAP}\left(R^{2}=0.972, p<0.05\right)$.

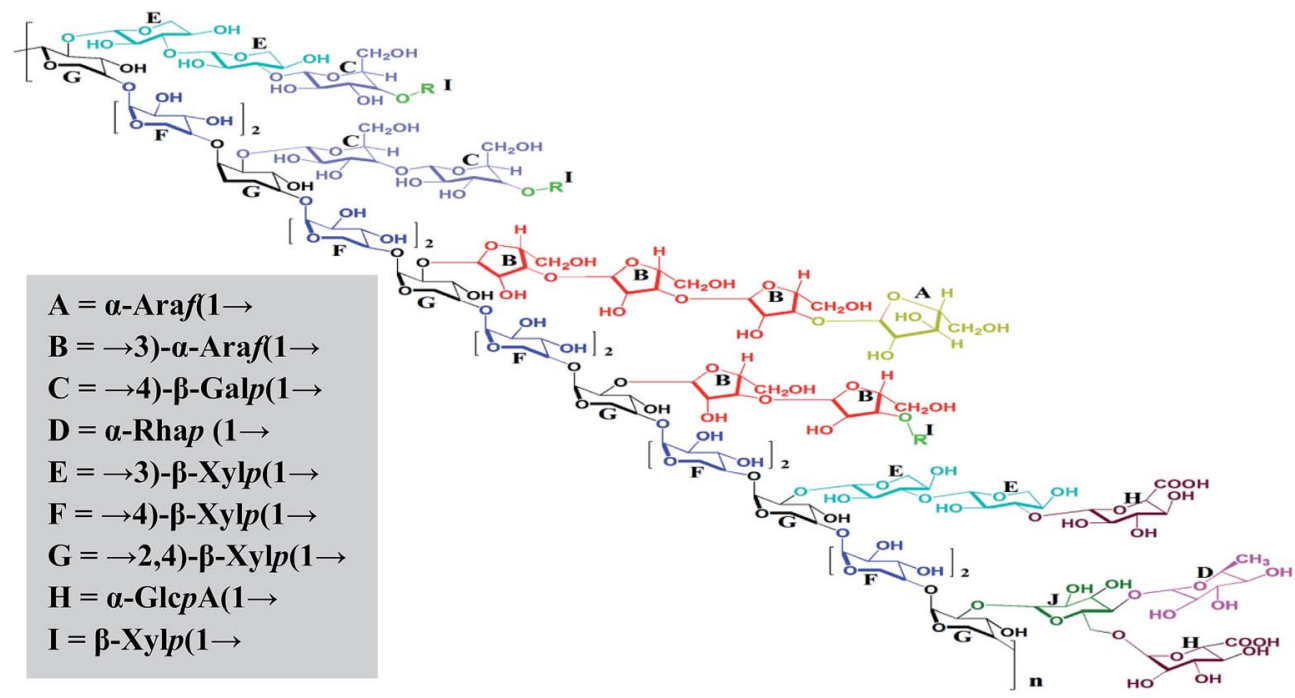

Fig. 5 The proposed structure of MAP, R = t-Xylp with a free reducing end. Note: stereochemistry was not considered when drawing the structure.

scavenge DPPH radicals. ${ }^{75,79,80}$ In addition, recent research reports have indicated that pure polysaccharides have remarkable antioxidant activity. ${ }^{\mathbf{8 1 , 8 2}}$

In brief, the antioxidant activity of polysaccharides is dependent on their hydrogen atom donating ability and the capability of uronic acids to chelate metal ions. Thus, in the present study, the antioxidant activity of MAP is due to the uronic acids in the arabinoxylan backbone.

\section{Conclusion}

In the present study, an alkali-soluble polysaccharide (MAP) was isolated from the leaves of $M$. coromandelianum using $1 \mathrm{M}$
$\mathrm{NaOH}$ in $1.15 \%(w / w)$ yield and was found to reduce $\mathrm{Fe}^{+3}$ ions in a dose-dependent manner. Further, structural analysis showed that the polysaccharide is mainly composed of xylose (60.42 mol\%) and arabinose (18.36 mol\%), indicating that MAP is an arabinoxylan with an $\mathrm{A} / \mathrm{X}$ ratio of 0.3 . Based on GLC analysis, the molar ratios of monosaccharides L-rhamnose, $\mathrm{L}^{-}$ arabinose, D-xylose, D-glucose and D-galactose are 1.00, 6.04, 19.88, 1.07 and 3.03, respectively, and that of D-glucuronic acid is 1.95. The glycosidic linkage analysis showed that MAP consists of $\rightarrow 4)-\beta-X y l p(1 \rightarrow(30.09 \mathrm{~mol} \%)$ as a backbone with monosubstitution at $\mathrm{O}-2$ of $\rightarrow 2,4)-\beta-\operatorname{Xyl} p(1 \rightarrow(17.96$ mole $\%)$ with other sugar residues. $\rightarrow 3)-\beta-X y l p(1 \rightarrow(12.25 \mathrm{~mol} \%)$ and $\rightarrow 3)-\alpha$-Araf $(1 \rightarrow(15.21 \mathrm{~mol} \%)$ are the main side chain residues. 
The terminal residues in MAP are $\alpha$-Araf $(1 \rightarrow(3.19 \mathrm{~mol} \%), \alpha$ GlcpA $(1 \rightarrow(6.25 \mathrm{~mol} \%)$ and $\alpha-\operatorname{Rhm} p(1 \rightarrow(3.13 \mathrm{~mol} \%)$, respectively. The oligomeric pattern consisting of xylose residues was abundantly clarified from ESI-MS analysis of partial hydrolysates $(0.5 \mathrm{M}$ and $1 \mathrm{M} \mathrm{HCl})$ of MAP clearly indicated that xylose units are linked as oligomers (heptamer, hexamer, etc.). Based on the monosaccharide composition, methylation and partial hydrolysis studies concomitant with NMR analysis, MAP was found to be an arabinoxylan. Further, the reducing power of MAP was determined using the potassium ferricyanide assay, which showed dose-dependent behavior. These results may be useful to understand the biological and medicinal activities of the polysaccharide based on further structure-activity relationship studies, thereby offering an opportunity for better utilisation of a species widely used in traditional systems of medicine.

\section{Conflicts of interest}

The authors have no conflicts of interest to declare.

\section{Acknowledgements}

The authors are grateful to the Director, Forest Research Institute (FRI), Dehradun for providing laboratory facilities. Thanks are also due to Dr H. B. Naithani, Systematic Botanist, Forest Research Institute for authentication of the plant material.

\section{References}

1 V. Rana, M. K. Das, S. Gogoi and V. Kumar, Carbohydr. Polym., 2014, 102, 341-350.

2 L. Cai, S. Zou, D. Liang and L. Luan, Carbohydr. Polym., 2018, 184, 354-365.

3 Y. Chen, F. K. Yao, K. Ming, D. Y. Wang, Y. L. Hu and J. G. Liu, Molecules, 2016, 21, 1705-1728.

4 J. Ghosh and C. E. Myers, Proc. Natl. Acad. Sci. U. S. A., 1998, 95, 13182-13187.

5 S. Devi and V. Kumar, Arabian J. Chem., 2018 Feb 22, DOI: 10.1016/j.arabjc.2018.01.009.

6 M. A. Pahlavani and M. D. Harris, Free Radic. Biol. Med., 1998, 25, 903-913.

7 Z. J. Wang, J.-H. Xie, S.-P. Nie and M.-Y. Xie, Food Funct., 2017, 8, 915-926.

8 A. C. Díaz, M. L. Espino, N. S. Arzoz, S. M. Velurtas, N. M. A. Ponce, C. A. Stortz and J. L. Fenucci, Latin American Journal of Aquatic Research, 2017, 45(1), 104-112.

9 H. Xue, F. Gan, Z. Zhang, J. Hu, X. Chen and K. Huang, Int. J. Biol. Macromol., 2015, 81, 22-30.

10 Y. Jin, K. X. Liu, J. Y. Peng, C. Y. Wang, L. Kang, N. Chang and H. Sun, Toxicol. Lett., 2015, 232, 149-158.

11 S. L. Qiu, J. Chen, X. Chen, Q. Fan, C. S. Zhang, D. Wang, X. Li, X. Chen, X. Chen, C. Liu and Z. Gao, Carbohydr. Polym., 2014, 103, 148-153.

12 L. Fan, J. Li, K. Deng and L. Ai, Carbohydr. Polym., 2012, 87, 1849-1854.
13 Y. Wang, Y. Wang, D. Liu, W. Wang, H. Zhao, M. Wang and H. Yin, Carbohydr. Polym., 2015, 125, 135-145.

14 F. Meng, B. Zhou, R. S. Lin, L. Jia, X. N. Liu, P. Deng, K. Fan, G. L. Wang and J. Zhang, Bioresour. Technol., 2010, 101, 4564-4569.

15 S. Bisht, R. Kant and V. Kumar, Int. J. Biol. Macromol., 2013, 59, 214-220.

16 P. Kumar and V. Kumar, Carbohydr. Polym., 2017, 165, 205212.

17 A. K. Lakhera and V. Kumar, Int. J. Biol. Macromol., 2017, 94, 45-50.

18 S. Nagar, A. Hensel, P. Mischnick and V. Kumar, Carbohydr. Polym., 2018, 193, 326-335.

19 V. Kumar, S. Nagar and Y. C. Tripathi, J. Biol. Macromol., 2014, 70, 360-363.

20 Anonymous, The Wealth of India: a dictionary of Indian raw materials and industrial products-raw material series, Publications and Information Directorate, Council of Scientific and Industrial Research, New Delhi, 1962, vol. VI, p. 251.

21 K. R. Kirtikar and B. D. Basu, Indian Medicinal Plants, 2nd edn, International Book Distributors, New Delhi, 1935, p. 306.

22 N. N. Sirkar, Pharmacological basis of Ayurvedic therapeutics, in Cultivation and utilization of Medicinal plants, Published by PID CSIR, 1989.

23 K. K. Ajibesin, B. A. Ekpo, D. N. Bala, E. E. Essien and S. A. Adesanya, Ethnobotanical survey of Akwa Ibom State of Nigeria Kola, J. Ethnopharmacol., 2008, 115, 387-408.

24 S. N. Srivastava, L. D. Kapoor, A. Singh and S. L. Kapoor, Survey of Indian plants for saponins, alkaloids and flavonoid, Lloydia, 1969, 32, 297-304.

25 M. Jiaying, Method for manufacturing traditional Chinese medicine preparation for treating gout, CN 102302706 A 20120104, 2012.

26 F. Z. Shenqing, Traditional Chinese medicine preparation for treating rheumatic arthralgia, CN 102366576 A 20120307, 2012.

27 L. Xin and H. He, Veterinary Chinese medicinal composition for treating laying hen salpingitis and its preparation method, CN 103735832 A 20140423, 2014.

28 B. Jialin, Chinese medicine for treatment of otitis media and its preparation method, CN 103656297 A 20140326, 2014.

29 N. Jiqiang, Traditional Chinese medicine composition for treating tumor, CN 103393743 A 20131120, 2013.

30 C. Hanting, F. Zhiwei, S. Yide, H. Qiaoqiao and L. Xiaoxia, Herbicidal composition for Manihot esculenta field, CN 103392703 A 20131120, 2013.

31 P. Changding, Medicinal wine and its preparation method, CN 103301401 A 20130918, 2013.

32 A. B. Deore, V. D. Sapakal and N. S. Naikwade, PharmacologyOnLine, 2011, 3, 147-154.

33 J. Sukanya, J. Apijade, J. Mongkol and W. Kamol, Plant compositions having oral insulin-like hypoglycemic activity and hypolipidemic and antimicrobial activities, Eur. Pat. Appl. EP, 1723960 A1 20061122, 2006. 
34 P. Khonsung, S. Nantsupawat, S. N. Jesadanont, V. Chantharateptawan and A. Panthong, Thai Journal of Pharmacology, 2006, 28, 3.

35 S. Chaiyasit, J. Sukanya, P. Pintip, N. Penphun and P. Sunanta, Curr. Res. Bacteriol., 2008, 1, 42-45.

36 P. Jain, D. Bansal, P. Bhasin and A. Anjali, J. Res. Pharm., 2010, 3, 1260-1262.

37 C. L. Leivas, M. Iacomini and L. M. C. Cordeiro, Carbohydr. Polym., 2015, 121, 224-230.

38 J. O. Schreck and W. M. Loffredo, Qualitative Testing for Carbohydrates, ed. H. Anthony Neidig, Che. Edu. Reso., 1994, vol. 3.

39 R. Katoch, Analytical Techniques in Biochemistry and Molecular Biology, Springer, 2011, p. 69.

40 W. E. Trevelyan, D. P. Proctor and J. S. Harrison, Nature, 1950, 166, 444-445.

41 R. L. Taylor, J. E. Shively and H. E. Conard, Stoichiometric reduction of uronic acid carboxyl groups in polysaccharide, in Meth. in Carbo. Chem., ed. R. L. Whistler and J. N. Be Miller, 1976, vol. 7, pp. 149-151.

42 P. E. Jansson, L. Kenne, H. Liedgren, B. Lindberg and J. Lonngren, Chem. Commun., 1976, 8, 1-76.

43 C. T. Bishop, Gas liquid chromatography of Carbohydrates derivatives, in Adv. in Carbohydr. Chem. and Biochem., ed. M. L. Wolfrom, 1964, 19, p. 95-157.

44 R. L. Scott, Anal. Chem., 1979, 51, 936-941.

45 T. Narui, K. Takahashi, M. Kobayashi and S. Shibata, Carbohydr. Res., 1982, 103, 293-295.

46 M. H. Fischer, N. Yu, G. R. Gray, J. Ralph, L. Anderson and J. A. Marlett, Carbohydr. Res., 2004, 339, 2009-2017.

47 Q. Guo, S. W. Cui, Q. Wang and J. C. Young, Carbohydr. Polym., 2008, 73, 35-43.

48 J. Y. Yin, H. X. Lin, S. P. Nie, S. W. Cui and M. Y. Xie, Carbohydr. Polym., 2012, 88, 1395-1401.

49 J. Kang, S. W. Cui, G. O. Phillips, J. Chen, Q. Guo and Q. Wang, Food Hydrocolloids, 2011, 25(8), 1991-1998.

50 J. Yin, H. Lin, J. Li, Y. Wang, S. W. Cui, S. Nie and M. Xie, Carbohydr. Polym., 2012, 87, 2416-2424.

51 Y. Habibi, M. Mahrouz and M. R. Vignon, Carbohydr. Polym., 2005, 60, 319-329.

52 A. Hoije, C. Sandstrom, J. P. Roubroeks, R. Andersson, S. Gohil and P. Gatenholm, Carbohydr. Res., 2006, 341, 2959-2966.

53 Y. Sun, S. W. Cui, X. Gu and J. Zhang, Carbohydr. Polym., 2011, 85, 615-621.

54 F. Peng, J. Bian, P. Peng, Y. Guan, F. Xu and R. C. Sun, BioResources, 2012, 7, 4744-4759.

55 J. M. Dobruchowska, G. J. Gerwig, A. Babuchowski and J. P. Kamerling, Carbohydr. Res., 2008, 343, 726-745.

56 A. B. Samuelsen, I. Lund, J. M. Djahromi, B. S. Paulsen, J. K. Wold and S. H. Knutsen, Carbohydr. Polymer, 1999, 38, 133-143.
57 R. Schendel, A. Becker, C. E. Tyl and M. Bunzel, Carbohydr. Res., 2015, 407, 16-25.

58 Y. Zhang, G. Yu, B. Li, X. Mu and H. Wang, Carbohydr. Polym., 2016, 141, 238-243.

59 J. Jiang, F. Kong, N. Li, D. Zhang, C. Yan and H. Lv, Carbohydr. Polym., 2016, 147, 365-371.

60 R. A. Hoffmann, M. Roza, J. Maat, J. P. Kamerling and J. F. G. Vliegenthart, Carbohydr. Polym., 1991, 15, 415-430.

61 R. A. Hoffmann, J. P. Kamerling and J. F. G. Vliegenthart, Carbohydr. Res., 1992, 226, 303-311.

62 A. Nishizawa, Y. Yabuta and S. Shigeoka, J. Plant Physiol., 2008, 147, 1251-1263.

63 R. Morelli, S. Russo-Volpe, N. Bruno and R. Lo Scalzo, J. Agric. Food Chem., 2003, 51, 7418-7425.

64 K. R. Wehmeier and A. D. Mooradian, Free Radic. Biol. Med., 1994, 17, 83-86.

65 W. Van den Ende and R. Valluru, J. Exp. Bot., 2008, 60, 9-18. 66 Y. X. Sun and J. F. Kennedy, Carbohydr. Polym., 2010, 82, 510-514.

67 H. Wang, Y. M. Liu, Z. M. Qi, S. Y. Wang, S. X. Liu, X. Li and X. C. Xia, Curr. Med. Chem., 2013, 20, 2899-2913.

68 L. N. Malunga and T. Beta, Cereal Chem., 2015, 92, 29-36.

69 L. N. Malunga, M. Izydorczyk and T. Beta, Bioact. Carbohydr. Diet. Fibre, 2017, 10, 20-26.

70 T. C. T. Lo, C. A. Chang, K. H. Chiu, P. K. Tsay and J. F. Jen, Carbohydr. Polym., 2011, 86, 320-327.

71 W. C. Zeng, Z. Zhang and L. R. Jia, Carbohydr. Polym., 2014, 108, 58-64.

72 R. S. P. Rao and G. Muralikrishna, Phytochemistry, 2006, 67, 91-99.

73 J. Wang, S. Hu, S. Nie, Q. Yu and M. Xie, Oxid. Med. Cell. Longevity, 2016, 2016.

74 H. Wang, Y. M. Liu, Z. M. Qi, S. Y. Wang, S. X. Liu, X. Li and X. C. Xia, Curr. Med. Chem., 2013, 20, 2899-2913.

75 J. Li, Y. Liu, L. Fan, L. Ai and L. Shan, Carbohydr. Polym., 2011, 84, 390-394.

76 E. Tsiapali, S. Whaley, J. Kalbfleisch, H. E. Ensley, I. W. Browder and D. L. Williams, Free Radical Biol. Med., 2001, 30, 393-402.

77 L. N. Malunga and T. Beta, Food Chem., 2015, 167, 311-319.

78 C. Hu, Y. Zhang and D. D. Kitts, J. Agric. Food Chem., 2000, 48, 3170-3176.

79 H. Wu, T. Min, X. Li, L. Li, F. Lai, Y. Tang and X. Yang, Int. J. Biol. Macromol., 2013, 59, 90-95.

80 S. H. Al-Sheraji, A. Ismail, M. Y. Manap, S. Mustafa, R. M. Yusof and F. A. Hassan, LWT-Food Sci. Technol., 2012, 48, 291-296.

81 J. Chen, L. Li, X. Zhou, P. Sun, B. Li and X. Zhang, Food and functions, 2018, 9, 6337-6348.

82 Y. Tang, Z. Y. Zhu, Y. Liu, H. Sun, Q. Y. Song and Y. Zhang, Food and functions, 2018, 9, 2300-2312. 